\title{
Perspectives of energy transitions in East and Southeast Asia
} doi.org/10.1002/wene.364

Article Type:

- OPINION

ADVANCED REVIEW
C PRIMER

FOCUS ARTICLE
C OVERVIEW

SOFTWARE FOCUS

\section{Authors:}

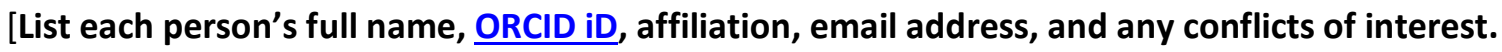
Copy rows as necessary for additional authors. Please use an asterisk $\left({ }^{*}\right)$ to indicate the corresponding author.]

\section{Bo Li}

School of Mechanical Engineering, Hubei University of Arts and Science, Xiangyang City, Hubei Province, China; hb lib@163.com

\section{Victor Nian*}

ORCID ID: 0000-0001-6679-7567; Energy Studies Institute, National University of Singapore, Singapore; nian@nus.edu.sg

\section{Xunpeng Shi*,}

ORCID ID: 0000-0001-9653-7395; Australia-China Relations Institute, University of Technology Sydney, Australia; xunpeng.Shi@uts.edu.au

\section{Hailong Li}

Future Energy Centre, School of Business, Society and Engineering, Mälardalen University, Sweden; hailong.li@mdh.se

\section{Augustin Boey}

Lee Kuan Yew School of Public Policy, National University of Singapore, Singapore; augustinboey@nus.edu.sg

\section{Abstract}

Energy transitions are designed to improve the resilience, sustainability and productivity of a country's energy system, and is a key instrument to mitigating the warming climate. Countries and regions have unique circumstances when projecting energy transition pathways. Nonetheless, East Asian economies have shared opportunities and challenges. From the perspective of fuel mix, East Asia had some initial success in renewable energy development accompanied by energy efficiency improvements. Nuclear energy, although controversial, has been well developed and is continuing its advancement in East Asia. However, the dominance of coal in the energy mix has not been 
sufficiently addressed, mostly because of legacy issues. The region's renewable energy potential is also underdeveloped due to a mismatch between resources and energy demand. Since the region as whole is well endowed with renewable energy resources, the region's advancement in regional energy connectivity presents a valuable institutional asset to further decarbonise East Asian energy sector beyond individual nation's efforts.

\section{Graphical/Visual Abstract and Caption}

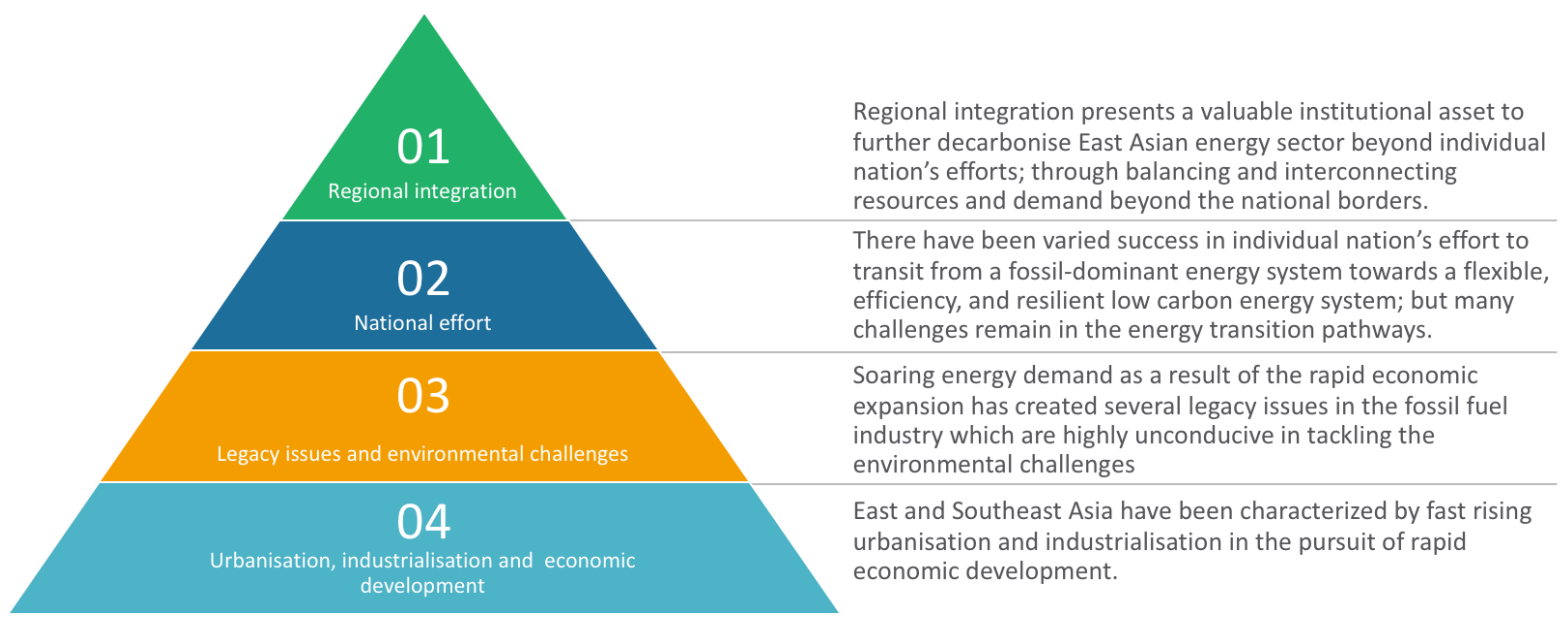

While rapid urbanisation and industrialisation are strong drivers for a transition towards a resilient low carbon energy system, many legacy issues remain in the East and Southeast Asian energy industry. The barriers in energy transition can be removed by looking beyond the national border towards regional integration and interconnection.

\section{Introduction}

Strong economic growth in East and Southeast Asia has driven a commensurately sharp increase in regional energy demand. This growth trend is expected to continue in the next two decades. According to the International Energy Agency (IEA, 2017a), China has shown particularly strong economic performance over a sustained period. China, having experienced a sustained period of two-digit percentage economic growth, has become the second largest economy in the world by purchasing power parity (IMF, 2017). China is now the world's largest manufacturing economy; the fastest-growing consumer market; and the world's largest exporter of goods and second-largest importer of goods (World Bank, 2018). This rapid increase in economic development has led to more than a tripling of energy demand from 1980 to 2005, though energy demand growth has slowed down in recent years following China's policy goal to lower the growth in energy consumption (EIA, 2018). China's total primary energy demand is expected to increase from 3005 million tonnes of oil equivalent (Mtoe) in 2015 to 4391 Mtoe in 2040 (IEA, 2018).

Likewise, the economies from the Association of South East Asian Nations (ASEAN) have also shown strong economic performance and has remained relatively resilient against the 2008-2009 global 
financial crisis. The regional GDP growth rate of about 5\% between 2000-2016 far exceeds that of the OECD average (1.6\%), and is comparable to that of India (7.2\%) and Africa (4.8\%) (World Bank, 2018). The ASEAN economy has almost doubled in size since 2000, reaching $\$ 6.1$ trillion in 2016, which is comparable to that of Japan and South Korea combined. The IEA (2017a) projects that ASEAN primary energy demand is expected to increase by $80 \%$ from 2013 to 2040 , largely driven by Indonesia, Thailand and Malaysia. The primary energy demand from ASEAN countries was 627 Mtoe in 2015, and is projected to grow at a rate of 3.4\% per year, reaching more than 1450 Mtoe in 2040 (ACE, 2017a). The strong momentum in expected energy demand growth has led both the Asian Development Bank (ADB, 2013) and the IEA (2017a) to predict the Southeast Asian region becoming a net-energy importer around 2030, a potentially dire situation due to the region's fossil fuel dominated energy mix.

\section{Fossil fuels dominance}

The growth of energy consumption in East Asia is, unfortunately, dominated by fossil fuels. Coal is abundant in China, and accounts for nearly $65 \%$ of China's primary energy consumption, at nearly 4 billion metric tons (IEA, 2018). According to BP (2018), China alone was responsible for half of global coal consumption in 2017. The need to satisfy the rapid increase in energy demand, and the practical constraints faced by solar and wind, are strong drivers of China's rising coal consumption. Despite the multitude of environmental efforts that have been implemented in recent years, China's consumption of coal has continued to increase (IEA, 2018).

The Fukushima disaster has precipitated Japan's shift from a low carbon economy towards a heavy reliance on imported fossil fuels. In particular, the needed nuclear capacity has been significantly replaced by imported LNG and coal (IEA, 2018), which has in turn caused a surge in energy import bills immediately after Fukushima (Matsuo \& Yamaguchi, 2013). LNG imports increased by almost $14 \%$, which brought the share of LNG in Japan's energy mix from $29 \%$ in 2010 to $43 \%$ in 2012 (Komiyama, 2013).

In ASEAN, coal has become the default option to make up for the rising energy demand. The expected sharp increases in energy demand will see the continued dominance of fossil fuels, in particular coal, in the ASEAN's energy mix: the share of fossil fuels will increase from $76 \%$ in 2016 to $78.6 \%$ in 2040, while coal's share in the TPES is expected to increase from $12 \%$ in 2015 to $23 \%$ in 2040 in the business as usual (BAU) scenario. Having experienced a double-digit annual growth rate since 1990, total demand for coal supplies in Southeast Asia is predicted to triple over the next two decades, from 116 Mtoe in 2015 to 329 Mtoe in 2040 (IEA, 2017b). As a result, coal is poised to overtake natural gas as the main fossil fuel to meet electricity demand starting in 2020 (ACE, 2017a). With Vietnam scrapping the plans for nuclear power plants (Asian Power, 2016), nuclear energy could be completely removed from the region's foreseeable future energy mix and replaced with coal, which could only worsen the region's net coal import situation.

\section{Social and Environmental challenges}

Continuing this trend of fossil fuel dependence amid sustained regional economic development will lead to significant and unacceptable environmental consequences. The significant increase in energy consumption (especially coal) in East Asian countries (IEA, 2017a) have caused significant environmental and health problems, as seen in Beijing and Jakarta (WHO, 2018). 
East Asia as an increasingly important contributor to global carbon emissions. Following its commitment to peak its emissions by 2030 , China's carbon emissions has gradually decreased from 9236 million metric tons (Mt) of carbon emissions in 2013 to $9101 \mathrm{Mt}$ in 2016 (IEA, 2018), but this decrease is more likely a reflection of the economic slowdown rather than a more sustainable in energy mix. Increasing fossil fuel consumption in ASEAN, particularly coal, is likely to cause ASEAN carbon emissions to rise from 1446 million tons (Mt) in 2015 to $3460 \mathrm{Mt}$ in 2040 in the BAU projections (ACE, 2017a). The additional carbon emissions from ASEAN between 2015 and 2040 is roughly equivalent to that of the world's fifth highest emitter (Japan) in 2014 (World Bank, 2018).

More stringent environmental policies have already been promoted in East Asia in response to the foreseeable rise in coal consumptions. In order to stop mitigate the devastating effects of air and water pollution, China has initiated a three-year environmental action plan to reduce the concentration of PM2.5 by $18 \%$ by 2020 from that of 2015 level. This plan includes an environmental tax for pollution discharges ranging from 1.2 to 12 Chinese Yuan for every unit of air or water pollution emitted (Chen, 2018). Renewable and nuclear energy technologies are options to address the environmental challenges, but their deployment faces varied practical challenges among East Asian economies.

Although moving away from the dependence on fossil fuels, coal in particular could bring tremendous environmental benefits, reducing dependence on coal means putting the multibillion dollar coal industry at stake. More critically, since the coal industry comprises mainly state-owned enterprises, replacing coal with other energy resources can induce a system-wide impact on the entire coal supply chain from mining to heat and power production, potentially jeopardising hundreds of thousands of jobs. These economic and social impacts could in turn translate to serious damages to the balance of political power within and across East and Southeast Asian economies.

\section{Energy transition in East and Southeast Asia}

The fossil fuel dominance and the consequent carbon emissions and other environmental challenges justify energy transition. The United Nations Economic and Social Commission for Asia and the Pacific (UNESCAP, 2018) has called for energy systems transitions towards socially, economically and environmentally sustainability, in order to achieve the Intended Nationally Determined Contributions (INDC), amongst other national and global goals. Nevertheless, for the majority of countries in the region, national INDC commitments are still insufficient compared to their historical obligations and capabilities (Gao et al., 2019). East and Southeast Asian energy systems thus require firmer intervention to meet the urgent need for climate action, and to attain other Sustainable Development Goals (United Nations, 2015).

East Asian countries have devoted significant efforts to improve energy efficiency. In China, the most notable energy efficiency improvement measure is the electrification of road transport (Nian, Hari, \& Yuan, 2019). In Japan, energy efficiency improvements and renewables could play an important role in Japan's post-Fukushima energy transition. With Thailand, Singapore, and the Philippines as the leaders, various energy efficiency measures have been implemented in ASEAN countries since 1990s (Shi, 2015). Despite that the level of energy efficiency development is unbalanced across ASEAN members, collectively, ASEAN achieved a 19\% reduction in energy intensity from 2005 to 2015. According to ACE (2017b), ASEAN aims to reduce the region's energy intensity by 20 percent by 2020 ,and 30 percent by 2025, both based on 2000 levels. 
Renewables have been increasingly adopted, driven both by the global impetus to mitigate carbon emissions, and by national prerogatives of address energy security. In 2017, China invested 127 billion US Dollars in renewable energy with 53 gigawatt of solar (Hodges, 2018) and 15 gigawatt of wind (Liu, 2018), as compared to 40.5 billion US Dollars renewable energy investments by the United States. Driven by fast declining costs and counter-balanced by strong curtailment due to grid constraints, $26.73 \%$ of China's electricity is produced from renewable energy sources with hydropower being the major contributor while solar and wind energy on a fast rising trend (IEA, 2018). China is currently the global leader in solar and wind energy market. Japan, despite having limited resources for renewable energy development, has initiated an ambitious plan for renewable energy deployment to address both energy and other strategic considerations (Kyodo, 2018).

However, the unbalanced access to technology is limiting the large-scale implementation of renewables in ASEAN. According to the IEA (2017a), ASEAN is generally well endowed with renewable energy resources albeit varied access from the perspective of costs and technical performance. The technical potential for renewable deployment in Southeast Asia is approximately 150 gigawatt of hydropower, 90 gigawatt of bioenergy, tens of gigawatts of wind, and minimum grid connected PV and solar thermal (Shi, 2016). However, access to each renewable energy technology varies significantly across ASEAN Member States. Despite such a limitation, ASEAN has also made significant progress in renewable energy development. According to ACE (2017b), the total installed capacity for renewable energy has doubled by 2015 since the 2007. Renewable energy share in ASEAN has increased from 9.6 percent in 2005 to 13.6 percent in 2015. I

\section{The role of nuclear energy in East and Southeast Asian energy transitions}

Nuclear energy provides a national solution if there is no better low carbon energy sources. Nuclear has a strong presence in East Asia, with Japan (prior to Fukushima) and South Korea being among the world's leaders in nuclear energy generation, and China quickly catching up (Nian, 2018b). Nuclear is attractive to the region for its low emissions, affordable prices and potential to enhance energy security. Maintaining a significant share of nuclear energy is of strategic importance to Japan from the perspective of international security and safeguards (Armitage \& Nye, 2012; Kitazume, 2012), global nuclear industrial development (Acton, 2013) and cooperation (Panda, 2013), among other strategic considerations. Reducing its dependence on coal-fired generation, China leads the world in terms of number of nuclear reactors under construction, and is the only East Asian economy remain committed to expand nuclear energy post-Fukushima (WNA, 2019).

Both Korea and Japan plan to keep about $30 \%$ of nuclear power in the generation mix to address energy security concerns, given their status as energy resource-poor countries (Yao, Shi, \& AndrewsSpeed, 2018). Even after Fukushima, several ASEAN members remained interested in nuclear energy to address base-load electricity supply (Nian \& Chou, 2014). Due to consideration over intermittency, cost of grid integration and land space, many countries in Southeast Asia had expressed increasing interest in nuclear energy since it is the only economically competitive low carbon option for diversifying the base-load electricity supply (Nian \& Chou, 2014; Nian \& Hari, 2017). Although ASEAN's interest might have been dampened with Vietnam's decision to scrap the planned nuclear power in 2016 (Asian Power, 2016), recent developments in advanced nuclear technologies or concepts might yet revive regional momentum in nuclear energy developments. These advanced nuclear reactor technologies, especially the small modular reactors developed in 
the latest wave of Generation IV technologies, have the potential to transform the clean energy landscape for the developing economies in East Asia and Southeast Asia (Nian, 2017), in addition to renewable energies.

Despite its low carbon potential, nuclear power remains highly controversial, and the role of nuclear power in East and Southeast Asian energy transitions over the long run is difficult to predict. The cost-competitiveness of nuclear energy over the planning horizon is highly uncertain, especially given the rapidly falling costs of renewable and energy storage technologies. There are risks associated with the management and long-term storage of radioactive nuclear waste in the traditional nuclear fuel cycle. More crucially, only very few countries in East and Southeast Asia are well versed in nuclear power technology, while most others have little to no experience in commercial nuclear power plant safety and security. Therefore, whether nuclear could plausibly play a significant role in East and Southeast Asian energy transitions in the foreseeable future is still an open question.

Nevertheless, without the benefit of its nuclear generation capacity, Japan faces serious challenges in meeting its climate action commitment. These challenges are obviously more acute for the majority of East and Southeast Asian countries with developing economies. While nuclear power generation remains contentious worldwide, the Intergovernmental Panel on Climate Change has continued to acknowledge nuclear energy, alongside renewables, as important mitigation options to attain the "zero emission scenario" in its latest assessment report (IPCC, 2014). Japan's case illustrates the practical importance of nuclear generation in supporting a high level of GHG mitigation ambition. In 2009, Japan committed to a 25\% reduction in emissions from 1990 levels by 2020. However, in the post-Fukushima political environment of 2013 , revised its commitments downwards to a $3.8 \%$ reduction from 2005 levels, which translates to a $3.1 \%$ increase in GHG emissions from 1990 levels (Watanabe \& Morales, 2013).

\section{Regional integration}

Despite limited low carbon options and the slow development of nuclear energy, energy transition could still be materialized through regional integration. The East Asian region has vast untapped renewable energy potential, and could potentially provide low-emission electricity at current price levels. As mentioned earlier, the ASEAN region has only achieved a small fraction of the technical potential for renewable energy deployment. Barriers to renewable energy development include not only technological capacity and access to finance, but more importantly, a geographical mismatch between resource endowments and demand centres (Shi, 2016). The uneven distribution of lowcarbon resources, and the mismatch between resources and demand centres, implies the need for regional inter-connection in power grids to bridge demand and production. The recent surge in variable renewable energy capacity, mainly solar and wind, only add more incentives for regional power connectivity.

Regional energy connectivity has achieved some initial success in the East and Southeast Asian region and its further development could present additional opportunities to advance sustainable energy transitions at the regional level without necessarily compromising costs, emissions and energy policy at national levels. ASEAN is a pioneer in regional connectivity in the Asia-Pacific region. Under the agenda of "one community for sustainable energy", ASEAN promotes several initiatives along the lines of regional integration, such as ASEAN power grid (APG) interconnection, trans- 
ASEAN natural gas pipeline (TAGP), energy efficiency and conservation, renewable, civilian nuclear energy, and regional policy and planning (Shi \& Malik, 2013). The APG is a collective effort to channel excess and ideally low carbon electricity such as hydropower along the Mekong River to countries with high demand for clean electricity (ACE, 2017b). APG capacity has increased from 3,489 megawatt in 2015 to almost 5,300 megawatt in 2017 (ACE, 2017b). As of May 2017, 14 cross-border interconnections have been established at 8 out of the 16 planned locations. The Lao PDR-ThailandMalaysia (LTM) pilot multilateral electricity trading project through a Cross-Border Power and Transmission Agreement was planned in September 2017, with an initial trading between Lao PRD and Malaysia starting in 2018 and the second phase of the pilot project is expected to enable trading between Lao PDR and Singapore by 2020 (Jiaxin, 2018). In 2016, ASEAN power trade reached a total amount of $5.2 \mathrm{GW}$, around $2.5 \%$ of the total regional installed capacity, and the share increases to $2.7 \%$ in 2017. ASEAN expects that power exchange and purchase among ASEAN member states will almost triple from $3.5 \mathrm{GW}$ in 2014 to $10.8 \mathrm{GW}$ in 2020, and further increase to $16 \mathrm{GW}$ post-2020 (APAEC, 2015).

The Greater Mekong Sub-region (GMS) has already achieved a power market integration among Cambodia, Myanmar, Lao PDR, Thailand, Vietnam and China. Under the GMS power framework, around 51.7 TWh electricity was exchanged between the participating ASEAN states with Yunnan and Guangxi provinces in China by the end of 2017 (China Southern Power Grid, 2017). The GMS power market integration has progressed ahead of the APG. The GMS countries have ongoing bilateral power trade and is making progress toward grid-to-grid power trading between any pair of GMS countries, with concomitant use of third countries transmission facilities for that trading (ADB, 2018). East Asian regional energy connectivity is likely to be further advanced in the coming decades as China is taking leadership for a global power interconnection. As announced by Chinese President Xi Jinping at the United Nations Sustainable Development Summit in 2015 (Halawa, James, Shi, Sari, \& Nepal, 2018), China has adopted Global Energy Interconnection, as both a policy and an initiative, in response to the need to mitigate climate change, pollution, and resource constraints. Geographical proximity, political alignments, and the spatiality of existing energy integrations in the region suggest that the bulk of any future integration efforts will likely remain between ASEAN and China.

However, despite initial success, achieving a complete energy interconnection in ASEAN will continue to face technical challenges, such as physical access and grid compatibility, barriers to cooperation and contractual arrangements, and other institutional challenges (Shi \& Malik, 2013). In addition, an economically efficient portfolio of power generation technologies, and hence the energy mix, is crucial for sustaining economic competitiveness while attaining climate objectives for ASEAN (Shi, 2016). Complicating this issue is the interminable heterogeneity between ASEAN member states, relating not only to absolute differences in their key economic indicators and development priorities, but also to critical differences in their political make-up, affiliations, and national interests (Henderson, 2014). Given the historical, and ongoing, divergences along these myriad sources of factiousness, the possibility of an extensive and stable Southeast Asian energy integration network is unlikely to be realizable within the isolated realm of energy policy. Rather, it is more likely ultimately conditional on the efforts and successes of broader attempts to establish a more thorough and comprehensive form of ASEAN regionalism.

\section{Energy transition in question}


Despite numerous energy outlooks for the energy sector in East and Southeast Asia, many questions and uncertainties remain for the future of energy transition pathways. All of these questions and uncertainties stem from the lack of political will and practical technology roadmaps customised for the economies and groupings in East and especially Southeast Asia. A prerequisite step towards the adoption of a diverse portfolio of mitigation technologies is the development of energy technology roadmaps with clearly labelled cost and technical characteristics. Without such information, it is difficult for ASEAN member states to evaluate the alternative pathways and potentials of decarbonisation under cost constraints, and thus to make sound policy decisions. The paradox between ASEAN's green aspirations and brown outlook of a coal dominated economy (Shi, 2016) is, at some level, a manifestation of the consequence caused by the lack of technology pathways. Essentially, policy makers are having a difficult time determining how to achieve their green vision from the pro-coal reality.

The majority of ASEAN members are developing economies; these countries also contain the vast majority of Southeast Asia's population. For these fledging economies, access to affordable energy remains the top priority; and policy generally tends to prioritize development over environmental considerations. As intimated in the preceding section, for sustainable energy transitions to be realized at a regional scale, there is an overarching need for more comprehensive coordination to reconcile the varying economic and environmental incentives between individual countries. This might also necessitate the co-design of accompanying mechanisms to address the complex tradeoffs and interdependencies involved in regionally coordinated energy transitions. With a suitable framework for cooperation, and a good understanding of technologies in place, one forward-looking question is how to establish a cross-sector policy framework to facilitate the co-development of fossil fuel replacement, energy efficiency and renewable energy in a sustainable, affordable and reliable manner.

There are many legacy questions to be addressed for the coal industry in China and the nuclear industry in Japan and Korea. The answers to these policy questions will have to come from a much stronger policy push, which is necessary to achieve the needed energy transition. Large economies like China and Japan are unlikely to deviate strongly from the trajectories set by their energy sectors, excepting the disruptive effects of major events such as the Fukushima Daiichi disaster. For the foreseeable future, the industrial and electricity sectors in East Asia will remain highly dependent on fossil fuels, with coal still playing an major role in national energy mixes. Nuclear energy remains a highly debated topic among those states that remain interested in it post-Fukushima, but there are many uncertainties over its viability over the long-term. Major technological breakthroughs in renewables and battery storage might enable energy transitions from fossil-dependence to a resilient low carbon energy system, but only if these technologies can be made competitive against coal. Similarly, a stronger and more extensive framework for regional coordination and cooperation might enable ambitious developments in electric grid interconnection between Northeast and Southeast Asia, holding the potential for sustainable energy transition pathways in East Asia, assuming sufficient political will from East and Southeast Asian states.

\section{Acknowledgments}


The paper is supported by Central government guides local science and technology development projects of Hubei Province (Grant No.2018ZYYD016), Natural Science Foundation of Hubei Province of China (No.2013CFB063), R\&D Project of Xiang Yang.

References

ACE. (2017a). The 5th ASEAN Energy Outlook 2015-2040. Retrieved from Indonesia:

ACE. (2017b). ASEANEN Energy Cooperation Report 2017. Retrieved from Indonesia: http://www.aseanenergy.org/resources/asean-energy-cooperation-report/

Acton, J. M. (2013). Two Nuclear Dilemmas for Japan. Retrieved from

ADB. (2013). Energy outlook for Asia and the Pacific. Mandaluyong City, Philippines: Asian Development Bank.

ADB. (2018). The Ha Noi Action Plan 2018-2022. Retrieved from Philippines:

https://www.adb.org/sites/default/files/institutional-document/409086/ha-noi-action-plan2018-2022.pdf

APAEC. (2015). ASEAN Plan of Action for Energy Cooperation (APAEC) 2016-2025. Retrieved from Indonesia: http://www.aseanenergy.org/wp-content/uploads/2015/12/HighRes-APAEConline-version-final.pdf

Armitage, R. L., \& Nye, J. S. (2012). The U.S. - Japan Alliance - Anchoring Stability in Asia. Retrieved from

Asian Power. (2016, 22 November 2016). Vietnam's nuclear implosion: Is the final decision a giant leap backwards? Asian Power. Retrieved from http://asian-power.com/project/infocus/vietnams-nuclear-implosion-final-decision-giant-leap-backwards

BP. (2018). BP Statistical Review of World Energy. Retrieved from United Kingdom:

Chen, J. (2018, 11 January 2018). Environmental tax to help China fight pollution. China Daily (English).

China Southern Power Grid. (2017). Social Responsibility Report. Retrieved from China: http://eng.csg.cn/Social Responsibility/Social Responsibility Report/201805/P0201805116 69351733058.pdf

EIA. (2018). International Energy Outlook 2018. Retrieved from USA: https://www.eia.gov/outlooks/ieo/zip/all detailed.zip

Gao, G., Chen, M., Wang, J., Yang, K., Xian, Y., Shi, X., \& Wang, K. (2019). Sufficient or insufficient: Assessment of the intended nationally determined contributions (INDCs) of the world's major greenhouse gas emitters. Frontiers of Engineering Management. doi:10.1007/s42524019-0007-6

Halawa, E., James, G., Shi, X., Sari, H. N., \& Nepal, R. (2018). The Prospect for an Australian-Asian Power Grid: A Critical Appraisal. Energies, 11(1). doi:10.3390/en11010200

Hodges, J. (2018, 5 April 2018). China Shines Bright as Solar Leads Record Renewables Investment. Bloomberg.

IEA. (2017a). Southeast Asia Energy Outlook. Paris, France: International Energy Agency.

IEA. (2017b). Southeast Asia Energy Outlook. Retrieved from

IEA. (2018). World Energy Outlook 2018. Paris, France: International Energy Agency.

IMF. (2017). World Economic Outlook Database. Retrieved 28 February 2019, from International Monetary Fund

IPCC. (2014). Climate Change 2014: IPCC Fifth Assessment Synthesis Report. Retrieved from Jiaxin. (2018, 30 March 2018). Energy, mines growth boosting Lao gov't revenues. Xinhua Net.

Kitazume, T. (2012, 3 November 2012). U.S. Needs Japan to Remain Nuclear, Expert Says. The Japan Times.

Komiyama, R. (2013). What Role Might Nuclear Power Play in Meeting East Asian Energy Demands ? In. Stanford University: NPEC: East Asian Alternative Energy Futures Workshop. 
Kyodo. (2018, 3 July 2018). Japan plans shift toward renewable energy, planning for first time to cut plutonium stockpile. The Japan Times.

Liu, Y. (2018, 3 April 2018). China's Wind Power Industry Expected to Rebound. Renewable Energy World.

Matsuo, Y., \& Yamaguchi, Y. (2013). The Rise in Cost of Power Generation in Japan after the Fukushima Daiichi Accident and Its Impact on the Finances of the Electric Power Utilities. Retrieved from

Nian, V. (2017). The prospects of small modular reactors in Southeast Asia. Progress in Nuclear Energy, 98, 131-142. doi:https://doi.org/10.1016/i.pnucene.2017.03.010

Nian, V. (2018a, 11 December 2018). Nuclear Power Becomes Critical to Arctic Dominance. Oilprice.com.

Nian, V. (2018b). Technology perspectives from 1950 to 2100 and policy implications for the global nuclear power industry. Progress in Nuclear Energy, 105, 83-98. doi:https://doi.org/10.1016/j.pnucene.2017.12.009

Nian, V., \& Chou, S. K. (2014). The state of nuclear power two years after Fukushima - The ASEAN perspective. Applied Energy, 136(0), 838-848. doi:http://dx.doi.org/10.1016/i.apenergy.2014.04.030

Nian, V., \& Hari, M. P. (2017). Incentivizing the Adoption of Nuclear and Renewable Energy in Southeast Asia. Energy Procedia, 105, 3683-3689. doi:https://doi.org/10.1016/i.egypro.2017.03.849

Nian, V., Hari, M. P., \& Yuan, J. (2019). A new business model for encouraging the adoption of electric vehicles in the absence of policy support. Applied Energy, 235, 1106-1117. doi:https://doi.org/10.1016/j.apenergy.2018.10.126

Panda, A. (2013). The Nuclear Problem in India-Japan Relations. In The Diplomat.

Shi, X. (2016). The future of ASEAN energy mix: A SWOT analysis. Renewable and Sustainable Energy Reviews, 53, 672-680.

Shi, X., \& Malik, C. (2013). Assessment of ASEAN Energy Cooperation within the ASEAN Economic Community. Retrieved from Jakarta: http://www.eria.org/ERIA-DP-2013-37.pdf

UNESCAP. (2018). Energy Transition Pathways - For the 2030 Agenda in Asia and the Pacific. Retrieved from USA:

United Nations. (2015). Transforming Our World: the 2030 Agenda for Sustainable Development Retrieved from New York:

Watanabe, C., \& Morales, A. (2013, 21 November 2013). Japan Cuts Emissions Goal in Setback for Climate Talks.

WNA. (2018). World Nuclear Performance Report 2018. Retrieved from London, UK:

WNA. (2019, February 2019). Nuclear Power in the World Today.

WNN. (2016, 4 August 2016). China and Indonesia to jointly develop HTGR. World Nuclear News.

World Bank. (2018). World Development Indicators. Retrieved 2 January 2019, from World Bank Group

Yao, L., Shi, X., \& Andrews-Speed, P. (2018). Conceptualization of energy security in resource-poor economies: The role of the nature of economy. Energy Policy, 114, 394-402. doi:https://doi.org/10.1016/i.enpol.2017.12.029 